1934 (J. Inst. Elec. Eng., Feb. 1935) is of general interest. The great technical progress made in broadcasting during the last two years is reflected in its rapid development. At the beginning of 1932, the number of licensed listeners in Europe was nearly 14 millions, and two years later it was nearly 20 millions. In 1929 the total power used in broadcasting was 420 kilowatts, whilst five years later it was more than ten times greater. Now that an average high-power station consumes 2 million electric units a year, it is important to use only transmitters of high efficiency. The extended use of short-wave telegraph working in ships has enabled the British P.O. stations to communicate regularly with whaling boats in the antarctic and in eastern waters. Directive aerials have been erected at these stations covering all the main shipping routes of the world, and this has greatly improved the services. Additional radio-telephone services from Great Britain to South Africa, Egypt and India have been opened up, while services to Japan, Shanghai, Kenya and Iceland are projected. By extension to circuits already existing, radio communication is now possible with nearly all the South American States. The outstanding feature in radio research has been the intensive study with the help of the cathode ray oscillograph of the propagation of waves in the ionosphere. The methods now in use indicate that the reflected signal resulting from a single pulse incident on the ionosphere consists frequently of a doublet the components of which are separated by a small time-interval. The reflected components are apparently electrically polarised waves of opposite rotational sense.

\section{Machine Mining and Labour Problems}

Authougr machine mining has made comparatively rapid progress during recent years, there is still room for a great advance in mechanisation. In a paper by Mr. J. Dooley, printed in the Mining Electrical Engineer of February, it is stated that in Yorkshire, which is one of the most progressive coal fields of Great Britain, only about one third of the coal produced is cut by machines and only about a sixth is loaded on to conveyor belts. There are a few coal seams from which coal simply rolls over into the 'tub', and it would be quite unnecessary to 'machine-cut' the faces of these seams. But even in these cases mechanical loading could be economic. ally applied by means of conveyors of suitable design. Another economic factor which has to be taken into account is the possibility of a shortage of suitable labour in the near future. This question may rapidly become acute as newer and more attractive industries and interests arise to attract the boys and young men who would otherwise automatically enter the pits. It is true that to some extent machines displace labour temporarily, yet the position may be reversed, and collieries be compelled to put in machines because sufficient labour is not available. It is essential for colliery managers to get to work with new ideas, and arrange and organise systems of work so that full advantage be taken of the existing types of machinery. There are machines already in use designed to carry enormous loads in supporting the roof and protecting other machines employed for cutting, loading and conveying coal simultaneously. American collieries have very large outputs per 'man shift', far in advance of anything ever attempted in Great Britain.

\section{Pacific Science Association}

THe Fifth Pacific Science Congress of the Pacific Science Association was held in Canada in 1933 under the presidency of Dr. H. M. Tory, president of the National Research Council of Canada. The Congress, which was held under the auspices of the National Research Council of Canada and through the generosity of the Government of Canada, was a notable achievement in the history of the Association. Representatives of no less than thirty-two countries attended the Congress, while the total number taking part in the meetings exceeded four hundred. The meetings were held in Victoria, B.C., on June 1-4 and in Vancouver, B.C., on June 5-14. The success of the Congress has now been crowned by the pub. lication of the Proceedings in five large volumes amounting to more than four thousand pages (Toronto : University of Toronto Press; London : Oxford University Press, 1934. 5 vols. 84s. net). These volumes form a noteworthy summary of scientific knowledge from many aspects contributed by research workers of those countries bordering the Pacific Ocean. It is clearly not possible to review the contents of these volumes, but mention should be made of the lavish hospitality extended to the members and participants by the Canadian authorities. The many social functions and the interesting excursions arranged for the entertainment of the visitors must have largely fulfilled one of the main objects of the Pacific Science Association, which is "to strengthen the bonds of peace among Pacific peoples by promoting a feeling of brotherhood among the scientists of all the Pacific countries". This alone should be sufficient tribute to the devoted care and energy given by those responsible for the organisation of the Congress.

\section{German Science}

A NEW quarterly review in English of German science has appeared under the title "Research and Progress" (Terramare Office, Berlin W.8), the editor being Dr. Karl Kerkhof. In the second number, which appeared in April, the articles are mostly geographical or cultural and historical in character. Prof. Erich von Drygalski discusses the effect of the polar regions on the history of the earth, dealing with the influence of currents of air from the pole from the physical, biological and human points of view, while Prof. Rudolf Spitaler considers the influence of shifts in the earth's axis on the production of earthquakes. Prof. Diedrich Westermann deals with a subject on which he has already made his views familiar to English readers - the changing African. The introduction of syphilis from the New World in 1493 is characterised by Prof. K. Sudhoff as a legend; it is suggested, however, that it may have spread by earlier contacts between the old 